\title{
Treatment seeking and health financing in selected poor urban neighbourhoods in India, Indonesia and Thailand
}

\author{
Jens Seeberg ${ }^{\mathrm{a}, *}$, Supasit Pannarunothai ${ }^{\mathrm{b}}$, Retna Siwi Padmawati ${ }^{\mathrm{c}}$, Laksono Trisnantoro ${ }^{\mathrm{c}}$, \\ Nupur Barua ${ }^{\mathrm{d}}$, Chandrakant S. Pandav ${ }^{\mathrm{e}}$ \\ ${ }^{a}$ Department of Culture and Society, Aarhus University, Moesgaard, DK-8270 Hoejbjerg, Denmark \\ ${ }^{\mathrm{b}}$ Centre for Health Equity Monitoring, Faculty of Medicine, Naresuan University, Thailand \\ ${ }^{\mathrm{c}}$ Faculty of Medicine, Gadjah Mada University, Indonesia \\ ${ }^{\mathrm{d}}$ Department for International Development (DFID), British High Commission, India ${ }^{1}$ \\ ${ }^{\mathrm{e}}$ Centre for Community Medicine, All India Institute of Medical Sciences, India
}

\section{A R T I C L E I N F O}

\section{Article history:}

Available online 3 December 2013

\section{Keywords:}

India

Indonesia

Thailand

Health seeking

Health finance

Universal health coverage

Inequity

Poor urban neighbourhoods

\begin{abstract}
A B S T R A C T
This article presents a comparative analysis of socio-economic disparities in relation to treatmentseeking strategies and healthcare expenditures in poor neighbourhoods within larger health systems in four cities in India, Indonesia and Thailand. About 200 households in New Delhi, Bhubaneswar, Jogjakarta and Phitsanulok were repeatedly interviewed over 12 months to relate health problems with health seeking and health financing at household level. Quantitative data were complemented with ethnographic studies involving the same neighbourhoods and a number of private practitioners at each site. Within each site, the higher and lower income groups among the poor were compared. The lower income group was more likely than the higher income group to seek care from less qualified health providers and incur catastrophic health spending. The study recommends linking quality control mechanisms with universal health coverage (UHC) policies; to monitor the impact of UHC among the poorest; intervention research to reach the poorest with UHC; and inclusion of private providers without formal medical qualification in basic healthcare.
\end{abstract}

(c) 2013 Elsevier Ltd. All rights reserved.

\section{Introduction}

This article presents a comparative analysis of socio-economic disparities in relation to treatment seeking strategies and healthcare expenditures in poor neighbourhoods within larger health systems in four cities in India, Indonesia and Thailand. The findings have implications for interventions that aim at increasing access to healthcare facilities in poor urban neighbourhoods similar to those included in the study.

Studies on treatment seeking behaviour vary widely in terms of scope, methodology and conceptual framework. Kroeger proposes a distinction between pathway models that focus on steps in the decision-making process and illness concepts that inform these steps; and determinants models that attempt to identify and quantify variables associated with choice of treatment (Kroeger, 1983).

\footnotetext{
* Corresponding author.

E-mail addresses: jseeberg@hum.au.dk, jseeberg@me.com (J. Seeberg).

1 Affiliated to affiliation e during project presented here; any views or opinions expressed are those of the author and do not necessarily represent or reflect those of DFID.
}

Medical anthropology on treatment seeking has tended to favour pathway models and may privilege "culturally specific illness beliefs and decision-making processes as determinants of treatment seeking in medically pluralistic contexts" (Evans \& Lambert, 1997, p. 1799). However, the determinants model can easily produce meaningless results in the absence of clear definitions of concepts and of analysis of the underlying rationale in people's decisions concerning self-care (Kroeger, 1983, p. 156), and he suggests that a combined approach may be more fruitful. We suggest that both approaches should be informed by a political economy of healthcare and analysis of relevant contexts of socio-economic inequity, especially in resource-poor settings.

\section{Methods}

The present study was part of a multi-disciplinary project on the role of private healthcare providers in poor neighbourhoods in selected cities in India (Bhubaneswar and Delhi), Indonesia (Jogjakarta) and Thailand (Phitsanulok). Both quantitative and qualitative methods were used. The qualitative studies have been or will be published elsewhere (Barua \& Pandav, 2011; Barua, Seeberg, \& 
Pandav, 2009; Seeberg, 2012, 2013). The interpretation of quantitative findings below is informed by this qualitative research.

A health economics household survey was conducted in four repeated rounds, using a modified version of an existing questionnaire (Pannarunothai \& Mills, 1998). Cities were selected relative to the involved research institutions. Purposive sampling was used to identify neighbourhoods within these cities according to the following criteria: a) access granted by local authorities, b) number and availability of private health clinics and providers of different medical systems in the area, c) minimal practical or other barriers to carrying out the study. Since official information was not necessarily accurate and complete, a mapping of the neighbourhood was conducted for each site. In the two Indian sites, GPS was used for this purpose. Keeping the same sample size across sites, approximately 200 households were selected randomly within participating neighbourhoods, on the basis of total number of households $/ 200=n$, including every $n$th household, or the neighbouring household if nobody responded or members did not wish to be included. Very few households refused to participate. Teams of male and female research assistants were involved in data collection, and data were subsequently analysed by the authors.

Key informants (head of household or the spouse of the head of household) were interviewed as proxy respondents of all household members about household demography, income, spending, health status, and treatment-seeking strategies, and a majority of key informants were female. Households were interviewed every three months over a 12 month period during 2004-2006.

Accuracy and precision of income and expenditure data based on interviews may fluctuate across sites depending on interviewer variation and external factors, but are assumed to be relatively stable within each site. The instrument was pilot-tested in all field sites and modified according to the outcome. In Delhi, the initial round of data had to be disregarded due to validity problems; hence only three rounds of data were available from this site. In Phitsanulok, due to frequent migration of people in the poor neighbourhoods, replacement of new households was attempted for subsequent rounds of household surveys but a substantial depletion of households occurred.

Data were checked and entered into SPSS v.19 as a single data set for comparative analysis. Income indicators included: reported individual and household income, disaggregate household expenditures and assets, in addition to sources such as savings, loans, insurance benefits and inheritance. Questions also captured selfreported illness episodes within last 30 days, any treatment expenditures, and use of conventional or complementary, public or private treatment facilities. Households were divided into a poor higher income group (Hi-IG) and a poor lower income group (LoIG) on the basis of the last round of data collection, using the median monthly household income as the cut-off point. This approach facilitated comparison of household health characteristics within the study area and across countries. Households remained in the same income group irrespective of changes in economic situation to keep group composition constant, with the fourth (last) round of data collection as index since rapport building over four rounds was expected to increase validity of data. Reanalyses on income did not show much fluctuations of income between the four rounds and most households consistently stayed in either Hi-IG or Lo-IG (see Supplementary data file 1 on validation of income groups). Household per capita income was used to compare household economic status because each country had different equivalence scales to weigh household economic status according to the economies of scale and lower spending on children as compared to adults (Koulovatianos, Schröder, \& Schmidt, 2005).

Limitations of the study include an element of convenience in the sampling strategy; depletion of households over time in
Phitsanulok; potential inaccuracy of self-reported income and illness data; and contextual differences across the neighbourhoods that impact on cross-neighbourhood comparison. The project was approved in India by the Institute Ethics Committee, All India Institute of Medical Sciences, New Delhi (March 2004), in Thailand by the Ethics Committee on Human Research, Naresuan University (October 2004) and in Indonesia by the Ethical Review Board of Gadjah Mada University (March 2002).

\section{Research sites}

\section{India}

India has the second-largest population in the world with a gross national income (GNI) per capita that has more than tripled during the decade from 2001 to 2011 (from USD 450 to USD 1420). Life expectancy at birth has increased from 64 (2004) to 65 years (2011). At the time of initial data collection in 2004, GNI was USD 597. In spite of the economic boom, 370 million people (29.8\% of the population) still lived below the poverty line in 2011, against $37.2 \%$ in 2005 (World Bank, 2013). The extent of chronic poverty in India remains staggering, and in the urban areas, one in three persons lives in abject poverty in slums, squatter settlements, construction sites, and on pavements.

\section{New Delhi}

In New Delhi, the national capital with a population of approximately 17 million (Census of India, 2011), Midan Puri (fictional names are used for all neighbourhoods) was selected for the study. It was a slum settlement located in New Delhi near one of the city's most affluent neighbourhoods. With an estimated population size of $25-30,000$, it was composed almost entirely of migrants from all over India. A typical area of "concentrated disadvantage" (Vlahov et al., 2007), the settlement had densely packed shelters; many built with concrete and tin roofs but a majority with flammable roofs. Single room hutments of approximately $50 \mathrm{~m}^{2}$ served as an all-purpose room generally demarcated into a sleeping area and a cooking area. All the houses were served by illegal electricity connections provided by a local "contractor" for a monthly fee. There was no regular water supply in the settlement. The inhabitants were dependent on two communal water sources which provided water for two hours in a day and on water tankers that came once a day, and often in the summer once in two days, from the Delhi Water Supply Department (Barua et al., 2009). Health services were provided by two free dispensaries run by NonGovernmental Organizations and 17 private practitioners in the neighbourhood. In addition, the inhabitants of the area also visited individual medical practitioners who operated clinics in two congested market areas outside the neighbourhood within a radius of around $4 \mathrm{~km}$ from Midan Puri.

\section{Bhubaneswar}

The second site in India was located in the state of Odisha with a population of approximately 42 million inhabitants (Census of India, 2011). It was one of the poorest states of the country with high rates of infant mortality and morbidity. Forty-six per cent of the population were illiterate, with a substantially higher level of illiteracy among women than men. The capital of Bhubaneswar had a population of approximately 838,000 people (Census of India, 2011). The city has experienced a high growth rate, and incoming migrants who typically belong to so-called scheduled tribes and castes often have no other option but to inhabit slum settlements, or bastis. In Bhubaneswar, Beluam basti was a small neighbourhood with a total of 520 households and a little more than 2000 inhabitants in 2004. It was surrounded by busy roads and 
intersections in the heart of the city, but was segregated from these by physical boundaries formed by high walls on two sides and a road on one side. The houses in the basti were evenly placed along lanes in an orderly manner and a few of the inner lanes were comparatively wider. The houses were small and consisted mostly of brick walls plastered with mud or cement and thatched roofs alternated with roofs made of asphalt or asbestos sheets. There was supply of electricity to the basti and about 50 households had legal connections, whereas the rest had either taken extensions from the legally connected ones or had hooked on to the scattered street lights. A number of water pumps supplied the basti with water and reflected power relations by being strategically but unevenly located. Some households had been able to install private water connections in addition to the community taps. Apart from one open drain at one side of the basti that benefitted about 50 households living in its vicinity, there was no provision for drainage or for disposal of solid or liquid waste from the households except for dumping areas where waste water and heaps of garbage accumulated. The absence of latrines was near total, so people had to defecate along the approach road and at the boundary wall.

\section{Indonesia}

Indonesia's population of 242 million (2011) is the fourthlargest in the world. GNI has almost tripled from USD 1070 in 2004 to USD 2940 in 2011, while 12\% of the population lived under the national poverty line in 2012 (15.4\% in 2008). Life expectancy at birth has increased from 67 years (2004) to 69 years (2011) (World Bank, 2013).

The Indonesian island of Java, with approximately 1000 people per sq. $\mathrm{km}$., is one of the most densely populated regions in the world. Jogjakarta in Central Java Province had a population of 3.5 million, and 390,000 people resided in the municipality (Statistical Body of Jogjakarta/BPS, 2010). In Jogjakarta, the study was conducted in two poor neighbourhoods, Kenongo Asri and Kalisari of $2.35 \mathrm{~km}^{2}$ with a total of 8105 households. The Kalisari river and the railway line cut through the area, and many poor people lived along them in unregistered houses made of bamboo or concrete. Most inhabitants had migrated from surrounding villages 20-30 years earlier. They had built houses on government land under the risk of eviction or rented small houses. Those, who could not afford to rent, built tents in the surrounding area. One neighbourhood was stigmatized as a kampong of thieves, robbers, prostitutes, and transvestites; in the other, the poor population survived as beggars, singing beggars, garbage collectors, tricycle drivers, and other types of informal sector labour such as laundering, ironing, parking attendance, porters, or selling cheap souvenirs to tourists.

Access to clean water, toilets and public facilities was very limited. Although public and private wells and water pumps were available in some places, many had to pay IDR 500-1000 per person per use of facilities, forcing a number of families to obtain water from the river for cooking, bathing and laundering.

\section{Thailand}

Whereas India and Indonesia are classified as lower middle income countries, Thailand is an upper middle income country with a GNI of USD 4440 in 2011 (USD 2460 in 2004) and a life expectancy at birth of 74 years (73 in 2004). Yet, $13.2 \%$ of the 70 million population lived under the national poverty line in $2011(20.9 \%$ in 2007) (World Bank, 2013).

Phitsanulok municipality has approximately 100,000 inhabitants and is located in the northern part of Thailand, $377 \mathrm{~km}$ from Bangkok. It is a centre for migration from rural areas of the lower northern part of Thailand. It was estimated that around 10\% of the population in Phitsanulok lived below the poverty line (Krongkaew, 2003). In Phitsanulok, two neighbourhoods - Rimpae and Klaipae - were included in the study; Rimpae, with approximately 1000 inhabitants (105 families), was located east of the Nan river and Klaipae was a resettlement area for approximately 1000 people, who had been forced by the local government to move from their boat houses on the river. Both areas had electricity and water supply. Many inhabitants in Rimpae had migrated from other places. Due to the high migration rate in Rimpae, many lived in temporary, rented dwellings. People in Klaipae stayed permanently and owned their houses but not the land. Many earned their living being hired on a day-to-day basis as construction workers, housekeepers, tricycle drivers, and working with laundry and ironing, and many migrated temporarily to other parts of Thailand for construction work or other jobs.

\section{Results}

\section{Household characteristics}

Table 1 provides a household profile of the four neighbourhoods. The number of household members was similar in Bhubaneswar and Jogjakarta, whereas the neighbourhood in Delhi had

Table 1

Number of households and their characteristics for each round.

\begin{tabular}{|c|c|c|c|c|}
\hline & Round 1 & Round 2 & Round 3 & Round 4 \\
\hline \multicolumn{5}{|l|}{ Bhubaneswar } \\
\hline Households & 201 & 196 & 192 & 188 \\
\hline Household members & 882 & 852 & 837 & 824 \\
\hline Average household size & 4.4 & 4.3 & 4.4 & 4.4 \\
\hline Dependency ratio, Lo-IG ${ }^{\mathrm{a}} / \mathrm{Hi}-\mathrm{IG}^{\mathrm{b}}$ & $3.1 / 2.3$ & & & \\
\hline Dependency Lo-IG:Hi-IG & 1.4 & & & \\
\hline $\begin{array}{l}\text { Mean per capita income } \\
\text { Lo-IG:Hi-IG }(\mathrm{Hi}-\mathrm{IG}=1)\end{array}$ & 0.31 & 0.33 & 0.34 & 0.34 \\
\hline $\begin{array}{l}\text { Per capita monthly } \\
\text { Lo-IG:Hi-IG (USD) }\end{array}$ & 0.57 & 0.56 & 0.53 & 0.55 \\
\hline \multicolumn{5}{|l|}{ Delhi } \\
\hline Households & & 205 & 206 & 206 \\
\hline Household members & & 1111 & 1122 & 1129 \\
\hline Average household size & & 5.4 & 5.4 & 5.5 \\
\hline Dependency ratio, Lo-IG/Hi-IG & & $6.0 / 5.0$ & & \\
\hline Dependency Lo-IG:Hi-IG & & 1.2 & & \\
\hline $\begin{array}{l}\text { Mean per capita income } \\
\text { Lo-IG:Hi-IG }(\mathrm{Hi}-\mathrm{IG}=1)\end{array}$ & & 0.42 & 0.44 & 0.44 \\
\hline Per capita monthly Lo-IG:Hi-IG (USD) & & 0.63 & 0.46 & 0.40 \\
\hline \multicolumn{5}{|l|}{ Jogjakarta } \\
\hline Households & 203 & 221 & 220 & 219 \\
\hline Household members & 853 & 882 & 882 & 856 \\
\hline Average household size & 4.2 & 4.0 & 4.0 & 3.9 \\
\hline Dependency ratio, Lo-IG/Hi-IG & $2.7 / 1.8$ & & & \\
\hline Dependency Lo-IG:Hi-IG & 1.5 & & & \\
\hline $\begin{array}{l}\text { Mean Per Capita Income } \\
\text { Lo-IG:Hi-IG }(\mathrm{Hi}-\mathrm{IG}=1)\end{array}$ & 0.42 & 0.43 & 0.41 & 0.38 \\
\hline $\begin{array}{l}\text { Per capita monthly } \\
\text { Lo-IG:Hi-IG (USD) }\end{array}$ & 0.52 & 0.54 & 0.57 & 0.70 \\
\hline \multicolumn{5}{|l|}{ Phitsanulok } \\
\hline Households & 175 & 62 & 57 & 57 \\
\hline Household members & 635 & 238 & 125 & 190 \\
\hline Average household size & 3.6 & 3.8 & 2.2 & 3.3 \\
\hline Dependency ratio, Lo-IG/Hi-IG & $3.8 / 2.9$ & & & \\
\hline Dependency Lo-IG:Hi-IG & 1.3 & & & \\
\hline $\begin{array}{l}\text { Mean per capita income } \\
\text { Lo-IG:Hi-IG }(\mathrm{Hi}-\mathrm{IG}=1)\end{array}$ & 0.29 & 0.44 & 0.49 & 0.33 \\
\hline $\begin{array}{l}\text { Per capita monthly } \\
\text { Lo-IG:Hi-IG (USD) }\end{array}$ & 1.07 & 1.51 & 0.67 & 0.47 \\
\hline
\end{tabular}

a $\mathrm{Hi}-\mathrm{IG}=$ poor higher income group. 
the largest households and Phitsanulok had the smallest. In the first round populations, the Indian poor neighbourhoods had the youngest population for the study with average age for Bhubaneswar being 23.0 (SD 16.2), Delhi 22.0 (SD 15.8), Jogjakarta 29.7 (SD 20.1), and Phitsanulok 32.4 (SD 18.5) years. There was almost equal representation of men and women in all four sites, with a male: female ratio for both Indian sites at 1:0.98, Jogjakarta 1:0.99 and Phitsanulok 1:1.02.

All households were divided into two groups, a low-income group (Lo-IG) and a high-income group (Hi-IG), with the median income as the cut-off point. We did not use an asset index because types and ownership of assets differed substantially between sites. In terms of dependency-age structure, the Lo-IG households constituted a younger population with a significantly higher percentage of children up to 14 years old and with a smaller elderly population $(p<0.01$ except in Phitsanulok, where it was not significant) compared to Hi-IG households.

Table 1 also shows the average number of dependants per income earner. Delhi had the highest number of family members reportedly not earning any income ( $>80 \%)$, and the Hi-IG in Jogjakarta had the least family members not earning (about $45 \%$ ). In all sites, the number of mouths to feed per income earner was higher in the Lo-IG than in the Hi-IG.

As mentioned in the methodology section, data on income and expenditure should be interpreted with some caution due to difficulties in obtaining accurate data. However, this issue is assumed to be stable across the two income groups within each site. The average income per capita of the Lo-IG was about one-third of HiIG. The Lo-IG households in Bhubaneswar were the most vulnerable with almost all income stemming from personal wages and salary. The Hi-IG families retained a higher proportion of income from other sources (such as rent, pension, insurance and sale of property) except in Phitsanulok (Table 1).

About half of family members in poorer Delhi families were children with the elderly constituting less than one per cent. Jogjakarta and especially Phitsanulok had a higher proportion of elderly population. The different age structures had implications on the number of income earners relative to dependants in the family (Fig. 1). Whereas the dependency-age structure was relatively stable over time in three sites, the depletion of the participating households due to migration in Phitsanulok showed that migrating families tended to have a smaller number of dependants than staying families. In the two sites in India, the household age composition showed a remarkable absence of young adults,

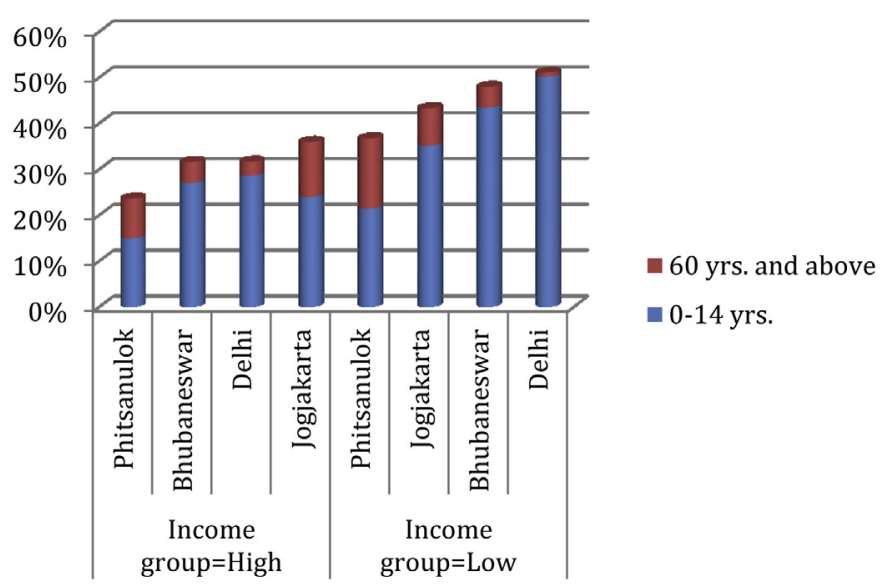

Fig. 1. Dependency-age structure of households, average of all rounds of data collection, four sites, sorted left to right with increasing number of dependants per household. especially in the poorer low-income group (see Supplementary data file 2 for detailed age/sex data). Fig. 1 shows that the Lo-IG households had a larger proportion of children and elderly, and the income data confirmed that they had more people not earning income relative to household size.

\section{Disposition of income}

Family spending data is used to reflect how households allocated their resources. Family spending among Lo-IG families was approximately half of that of Hi-IG families in except Phitsanulok where Lo-IG reported higher spending for the first two rounds, especially on non-food. Based on reported expenditure categories (data not shown), food took the major share of household spending in three cities except Phitsanulok. Spending on education was lower than spending on health.

Monthly income per capita and monthly spending per capita in this study were not weighted by age of the family members since equivalence scales varied in different sites. The poorer households tended to have a systemic deficit (Fig. 2). The composition of children in the family should not influence this comparison since income and spending data were divided by the same scale.

Reported illness and treatment responses in the context of medical pluralism

Treatment seeking in all four poor neighbourhoods was characterized by medical pluralism defined as the co-existence of different systems or traditions of medicine, such as western biomedicine, ayurvedic medicine, homoeopathy, acupuncture, and local herbal traditions. These systems are not necessarily mutually exclusive but co-exist and blend in various ways.

\section{India - New Delhi}

No universal coverage scheme for healthcare existed in India. Health insurance was linked to employment status and benefits for employees in the government and parts of the corporate sector. Public-sector primary healthcare was largely absent in urban centres. In New Delhi, health services were provided by the private sector in most poor neighbourhoods, as there was no government health centre. Poor people generally had to pay out-of-pocket for the services of private health facilities when they fell ill.

The public healthcare provision was fragmented and suffered from a lack of accountability, a poorly operating referral system, weak stewardship and poor staff quality and attitudes (World Bank, 2003). These posed major access barriers for the poor.

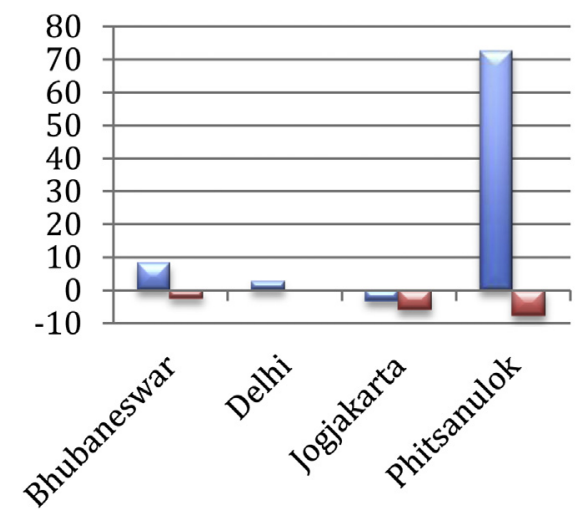

$\checkmark$ Hi-IG Per capita surplus/deficit

Lo-IG Per capita surplus/deficit

Fig. 2. Per capita monthly surplus/deficit (USD) for two income groups (mean, four rounds of data) (Hi-IG = poor higher income group, $\mathrm{Lo}-\mathrm{IG}=$ poor lower income group). 
Qualitative data showed that practitioners in Midan Puri did not possess any formal medical qualifications nor did they have licence to dispense biomedical drugs. Some of them had short-term diplomas in ayurveda and/or homoeopathy. Many had garnered 'medical experience' by working as helpers in clinics, hospitals and nursing homes or had been chemists at some stage. On an average, the patient load ranged from 10 to 25 day/clinic. During initial interviews most of them insisted that they were all 'registered practitioners' (RMP) of Indian Systems of Medicine but during 18 months of observation in these clinics we found that biomedical drugs were also prescribed or administered in all but a few cases. Fig. 3 shows the distribution of preferred healthcare providers across the four sites for the low and high-income groups, and the Delhi profile exhibits a much higher use of so-called complementary (i.e. non-allopathic) medicine than the other sites. We found this to be an expression of the merger at the clinical level of Indian and biomedical practice available inside the neighbourhood, as outlined above. All RMPs were found to primarily administer biomedical drugs, and antibiotics and steroids were given by private practitioners in response to ailments like common cold, cough, sore throat and fever. The demand, as one of the oldest practitioners in the neighbourhood succinctly summed up, was clearly for 'high powered medicines'. However, comparison of Hi-IG and Lo-IG groups in Delhi showed that the Hi-IG could afford to use Indian systems of medicine more often than the Lo-IG, and they were more often admitted to hospital in case of serious illness, whereas the Lo-IG would more often rely entirely on the RMPs.

\section{India - Bhubaneswar}

The health system in Bhubaneswar was also characterized by a pluralism of biomedical, homoeopathic, ayurvedic and traditional healing practitioners. But, in contrast to Delhi, in central Bhubaneswar the qualitative study did not find many practitioners without the required qualifications appropriate for their tradition. In Beluam basti, there were no practitioners of biomedicine and local treatment systems were in the hands of a few faith healers, herbalists and one ayurvedic practitioner. However, in the periphery of the neighbourhood, there were a few homoeopathic clinics and several chemists who acted as de facto primary healthcare providers. They practised diagnostic services and sold prescription drugs over the counter, based on their experience and ability to learn from prescriptions brought by patients who had in fact seen a medical doctor (Seeberg, 2012). In comparison with the other sites, inhabitants of Beluam basti had an extremely high proportion of untreated illness (47\% in Hi-IG, 60\% in Lo-IG) (Fig. 3), indicating that the threshold of severity of illness where it was considered necessary to spend money on treatment was substantially higher here than in the other sites. We believe the difference between

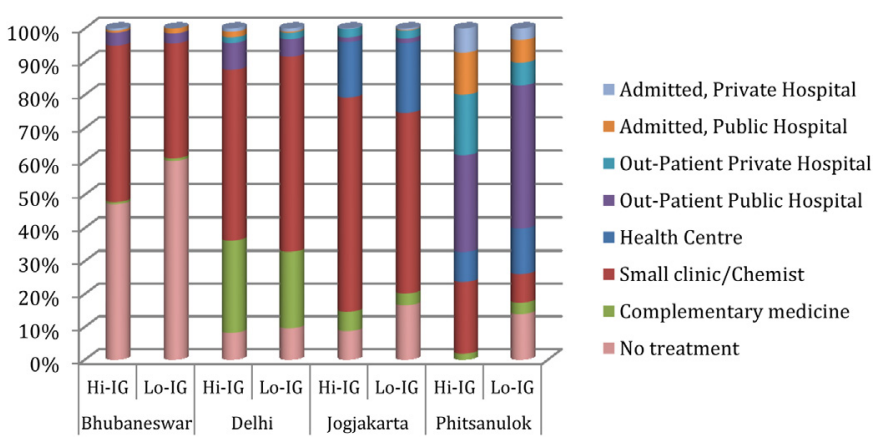

Fig. 3. Healthcare provider used in case of illness over four rounds of data collection, divided by income group and neighbourhood (Hi-IG = poor higher income group, Lo$\mathrm{IG}=$ poor lower income group).
Bhubaneswar and the other sites, and the difference in Beluam basti between income groups, is primarily related to poverty.

\section{Indonesia - Jogjakarta}

In Jogjakarta, each sub-district with the population of 25,000 or less had at least one public health centre and one sub-health centre. Each health centre had a general practitioner (GP), dentist, nurses, midwives, a laboratory analyst and a pharmacy assistant. The qualitative study showed that doctors, dentists and paramedical staff often had their own private practice in the evening or early morning outside office hours, either at home or at their private clinics. Besides the formal health facilities, small kiosks sold medicines and herbs. They were primarily consulted by people for illnesses such as common cold and cough, diarrhoea, fever, minor wounds, etc. Medical pluralism was also typical for Jogjakarta, where formal and informal, modern and traditional medical systems existed side by side. Traditional healers, faith healers, massagers, and herbalist were mostly consulted by people in poor neighbourhoods. In the two sites in Jogjakarta, there were more than 70 private providers practising, including small kiosks selling medicine, unlicensed drug stores, pharmacists, massagers, private doctors, nurses, traditional and trained midwives, herbalists and other forms of traditional medicine, small clinics and a small hospital. In Jogjakarta, participating households consulted at least nine doctors, three midwives, four nurses, two polyclinics, several pharmacies and small kiosks, and six traditional healers (massagers, faith healers and herbalist) during illness episodes.

Qualitative data showed that people did not use the different health providers interchangeably. For common cold and cough, fever and diarrhoea and breathing difficulty, they bought medicines from the local kiosk. They would name the medicines they usually bought for general health problems and take one or two tablets. If the condition did not improve in a day or two, they would seek other services, primarily the health centre or private practitioners. For more serious diseases, such as asthma, diabetes, and hypertension, they might consult either a doctor, a specialist, or a traditional healer until one was considered 'fit' or cocok. If the medicine was cocok, i.e., there was a 'fit' between the medicine and the specific disease in a person, the disease or symptom would be cured. Whether or not this fit would occur could not be predicted by patients or practitioners.

The profile of choice of healthcare provider for the Jogjakarta site shows that, in contrast to the two Indian sites, health centres are present and used by the studied neighbourhoods (21\% of Lo-IG and $21 \%$ of $\mathrm{Hi}-\mathrm{IG}$ ), but that chemists and small private clinics remain the main service providers (54\% for Lo-IG, $65 \%$ for $\mathrm{Hi}-\mathrm{IG}$ ). The proportion of untreated illness is almost double for the Lo-IG (17\%) compared to the Hi-IG (9\%) (Fig. 3).

\section{Thailand - Phitsanulok}

The health system in Thailand had a strong emphasis on primary care after the launch of the UHC policy in 2001; however, UHC was accompanied by a shortage of health staff in the primary care sector. In urban areas, large public and private hospitals were the main curative service providers. There were a few small hospitals at sub-district level and a municipality clinic providing basic primary care to a fraction of the urban population. People living in Phitsanulok tended to prefer private clinics, drug stores and practitioners of complementary medicine, and this pattern has not changed drastically after the introduction of the UHC scheme (Limwattananon, Tangcharoensathien, Tisayaticom, Boonyapaisarncharoen, \& Prakongsai, 2012; Pannarunothai \& Mills, 1997).

Qualitative data showed that, when faced with illness, most people in the two neighbourhoods in Phitsanulok would attempt to 
address the problem on the basis of available knowledge in the family or immediate community, using medicines from the drug store or herbal treatment. It was especially common for the elderly in this community to first turn to what has been described as a therapy management group (Janzen, 1987). This local, nonprofessional group comprised of lay people who played an important role in the interpretation of abnormal symptoms and decisions regarding treatment and disease management. Some of the management strategies suggested by this group included staying in bed, buying medicine from a grocery or drug store, praying or seeing health professionals at a medical clinic, primary care unit or hospital. Also, elderly people preferred to go to their usual drugstore. For what was perceived as more serious or persistent illness, people would seek professional healthcare providers.

The neighbourhood profile of healthcare used in Phitsanulok differs dramatically from the other sites in their comparatively frequent use of out-patient hospital services, with a higher use of private hospitals among the Hi-IG (18\%) than the Lo-IG (7\%) and the reverse situation for public hospitals ( $29 \%$ for Hi-IG, $43 \%$ for Lo-IG). Here, as well, we find the presence and use of health centres ( $9 \%$ for Hi-IG, 14\% for Lo-IG) and a substantial difference in frequency of no treatment ( $0 \%$ for Hi-IG, $14 \%$ for Lo-IG). Fig. 3 allows for comparison of the patterns of healthcare providers used across sites $(p>0.05$, mostly due to small sample size).

\section{Reporting of illness}

Responses to household interview asking illness within the past 30 days revealed that $6-26 \%$ of household members were ill $(0.7-$ 3.1 episode/person/year). Supplementary data file 3 provides an overview of symptom grouped by categories on the basis of a heuristic classification. Variation across sites is likely due to differences in background conditions, such as economical differences, and variation in sex and age composition as well as different explanatory models and idioms of distress across sites. Different explanatory models may cause a given medical condition to be classified differently across sites, and symptoms and diagnoses often merged. While the qualitative sub-studies provided in-depth information concerning individual illness trajectories, no systematic attempt was made in the household survey to relate reported symptoms with medically confirmed diagnoses.

At an aggregate level, the poor and the poorer family members reported similar occurrence of illness. While higher income group reported a higher incidence of symptoms of chronic conditions in some but not all sites, ear-nose-throat conditions and skin infections/sexually transmitted diseases tended to be more prevalent in the lower income groups. In some cases chronic conditions that produced the same symptoms for $>90$ days would be counted in several rounds; however, this would not account for the difference between the lower and higher income groups.

Das and Das (2006) have shown that a high level of background morbidity may result in underreporting of types of illness that are considered to be part of normal everyday life. Qualitative analysis confirmed that this was indeed the case, especially in Bhubaneswar (Seeberg, 2013), and - assuming a causal relation between poverty and ill health - it is likely that this type of underreporting may be more prevalent in the lower income groups compared to the higher income groups.

\section{Fee structure and health insurance}

\section{Delhi and Bhubaneswar}

Among non-qualified practitioners in the Indian sites, the qualitative study showed that prescriptions were never given and consultations were 'free' with a fee being charged 'only for the medicines'. Costing factors in relation to treatment did not necessarily follow a distinction between government and private services. While narratives of treatment seeking were replete with references to the high cost of medical care in the private sector, 'hidden costs' involved in utilizing government-provided care, clearly tipped the scale in favour of the private sector. Apart from vaccination programmes and antenatal care, the only exception to this pattern was found in the case of surgical procedures, which involved hospital stay. Often, including in the government sector, patients had to pay for services; or they would be referred to the private evening clinic of the treating doctor, as was found in Bhubaneswar and Jogjakarta. Therefore, it was never very transparent or predictable, how much money a consultation would cost, even if it was supposed to be free. The lack of free primary health facilities in urban India opened the market for a plurality of clinics offering health services, some of which were run by practitioners with dubious qualifications. Some had merely been working as helpers in doctors' clinics for a period of time before setting up own practice. In Delhi, these practitioners tended to be available inside the poor neighbourhood; they would offer services much cheaper than medically qualified practitioners, whereas an equivalent type of service was provided by chemists in Bhubaneswar. In both cities, the important decision in relation to costs was whether or not to see a medically qualified practitioner because it could involve paying a consultation fee as well as costly diagnostic tests and more expensive drugs.

\section{Jogjakarta}

In Jogjakarta, the qualitative data showed that most private practitioners used a fee-for-service strategy. There was no standard of payment and the price for healthcare services was determined by the practitioners. At the level of clinical interaction, in many cases there was a minimum of information from private practitioners about available treatment options, and often, these were not clear to the patients.

Health insurance for the poor (Askeskin or Asuransi Kesehatan Penduduk Miskin) was introduced by the government in 2004. Participating households would not pay for consultation or hospitalization in government facilities. The scheme only covered ten per cent of the population in the two sub-districts. Classification of eligible households was unclear and appeared to be manipulated locally, and many families who were poor according to our survey did not benefit from the scheme.

Other government interventions included a policy of earmarking some hospital beds for poor people; implementing the social safety net (Jaring Pengaman Sosial) in 1999 that had covered hospital care for the poor until it was replaced by Askeskin; and allowing the private hospitals to use the government health budget for poor families. In late 2005, government redirected money for gasoline subsidies to such pro-poor schemes, leading to increasing gasoline prices. Identification of eligible households was contested and non-transparent, and some families who expected to benefit, increased debt by spending it in advance only to realize that they were not classified as poor under the scheme. Among the approximately 200 families in this study, only six could benefit from the insurance schemes; the rest had to find other resources.

One such alternative option was to enrol in a local insurance scheme called community health insurance (Jaminan Pemeliharaan Kesehatan Masyarakat or JPKM), which was a government-funded health insurance scheme. It was older than JPS and limited to primary healthcare. Every month, a person from the JPKM would collect IDR 1000 (0.13 USD) per person. The insured would get a card to be presented in the hospital in case of health problems. 
Three months into our data collection, people refused to continue to pay due to mismanagement and difficulties when claiming the insurance.

\section{Phitsanulok}

In Thailand, the Ministry of Public Health was the principal agency responsible for promoting, supporting and coordinating all health service activities in the public and private sectors. Issues related to financing and consumer rights were handled by the government with different ministries in charge of specific issues.

The 30 Baht UHC scheme was implemented in April 2002. It covered the entire population by providing access to all medically needed treatment at primary healthcare units and hospitals against payment of a user fee of 30 Baht. In addition, insurance schemes existed for various sectors. An example of this was the Social Security Scheme that covered eight million workers.

UHC had directed many poor patients to use public facilities rather than the private sector. Both areas had a primary care unit that provided health services under this policy. However, migrants who were not registered as local citizens did not have access to public health services under the scheme and would therefore need to go to private practitioners when they faced health problems. This sector was not strictly regulated. For instance, there was no standardization in consultation fees being charged by private practitioners, or in the pricing of diagnostic procedures like $\mathrm{X}$-ray.

\section{Health expenditures}

Whereas Fig. 3 shows the use patterns of healthcare providers across sites and income groups, Fig. 4 shows the costs incurred by this use pattern.

Except for Bhubaneswar, where use of private hospitals is nearabsent, Fig. 4 illustrates the very substantial impact on health expenditures caused by relatively few cases of hospitalization. In terms of within-site comparison across the two income groups, we found that health expenditure was similar in the two income groups, except in the Phitsanulok sites, where the choice to access services under UHC was available and was utilized by the poorest (Table 2).

Catastrophic health expenditure describes a situation where health expenditures threaten a household's financial capacity to maintain subsistence needs (Su, Kouyaté, \& Flessa, 2006). Political decisions within each of the three countries regarding resource distribution determine coverage of risk-pooling mechanisms in health financing systems and the levels of out-of-pocket payment,

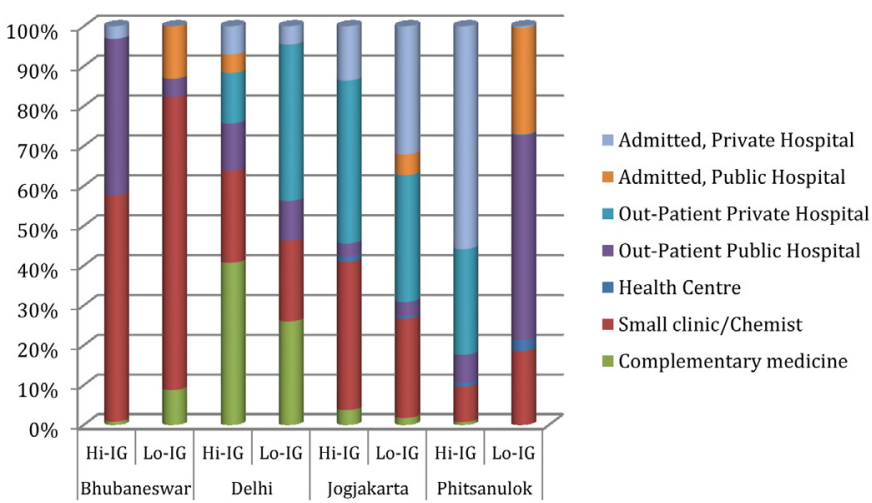

Fig. 4. Health expenditures/facility by income group for four neighbourhoods (HiIG = poor higher income group, Lo-IG = poor lower income group).
Table 2

Reported illness and health expenditure as mean, four rounds of data collection.

\begin{tabular}{lcclll}
\hline & \multicolumn{2}{c}{ Reported illness } & & \multicolumn{2}{l}{ Health expenditure as \%age of $\mathrm{PCI}^{\mathrm{a}}$} \\
\cline { 2 - 3 } \cline { 5 - 6 } \cline { 5 - 6 } & Hi-IG $^{\mathrm{b}}$ & LO-IG $^{\mathrm{C}}$ & & Hi-IG & Lo-IG \\
\hline Bhubaneswar & $9 \%$ & $8 \%$ & & $3 \%$ & $3 \%$ \\
Delhi & $15 \%$ & $15 \%$ & & $3 \%$ & $3 \%$ \\
Jogjakarta & $22 \%$ & $21 \%$ & & $1 \%$ & $1 \%$ \\
Phitsanulok & $10 \%$ & $12 \%$ & & $8 \%$ & $4 \%$ \\
\hline
\end{tabular}

${ }^{\text {a }} \mathrm{PCI}=$ per capita income.

b $\mathrm{Hi}-\mathrm{IG}=$ poor higher income group.

c Lo-IG $=$ poor lower income group.

and they influence the distribution of poverty that place some households at high risk of catastrophic health expenditure.

A uniform threshold for determining catastrophic health expenditure does not exist, and studies have variably calculated its incidence relative to total income/expenditures and non-food expenditures (Su et al., 2006). We have defined catastrophic illness as health-related expenditure that exceeds $10 \%$ of household income (Merlis \& Fund, 2002). Table 3 shows that the incidence of catastrophic health expenditures is higher in Lo-IG in all four sites. In Midan Puri (New Delhi), the incidence is extremely high. This is likely due to the near-total absence of public primary healthcare facilities combined with access barriers for the poor to utilize public hospitals in the city (Barua \& Pandav, 2011).

In the Bhubaneswar site, in many cases people in Lo-IG could not afford any treatment (Seeberg, 2013). Therefore, ironically, even if their risk of serious illness was high, the risk of catastrophic health expenditures was comparatively lower because they were not able to generate so much funding for treatment that it would be characterized as catastrophic. In addition, and in contrast to Delhi, the neighbourhood in Bhubaneswar had better access to public hospitals.

In Thailand, it is likely that the comparatively lower risk of catastrophic health expenditures is attributable to a combination of successful implementation of UHC and a relatively better economic situation. However, the figures also show that at the time of data collection, the risk of catastrophic health expenditures had not been eliminated by UHC. This finding is in accordance with other studies (Limwattananon, Tangcharoensathien, \& Prakongsai, 2007; Van Doorslaer et al., 2007).

As mentioned above, JPKM was being introduced without demonstrable success in Indonesia and the coverage of Askeskin was very limited at the time of data collection. The figures in Table 3 illustrate that the risk of catastrophic health expenditures in the participating neighbourhoods is considerable.

\section{Conclusion}

Above, we have combined qualitative and quantitative data in order to show that treatment-seeking strategies require a

Table 3

Incidence of catastrophic health expenditures in four neighbourhoods among total number of cases reporting any illness episode (total, four rounds of data collection).

\begin{tabular}{lrllll}
\hline & $\begin{array}{l}\text { \% Within } \\
\text { Hi-IG }\end{array}$ & $\begin{array}{l}\text { Total cases, } \\
\text { Hi-IG }\end{array}$ & $\begin{array}{l}\text { \% Within } \\
\text { Lo-IG }^{\mathrm{b}}\end{array}$ & $\begin{array}{l}\text { Total cases, } \\
\text { Lo-IG }\end{array}$ & $p$-Value \\
\hline Bhubaneswar & $12.7 \%$ & 440 & $18.3 \%$ & 339 & 0.03 \\
Delhi & $34.6 \%$ & 318 & $42.1 \%$ & 299 & 0.05 \\
Jogjakarta & $12.9 \%$ & 450 & $19.7 \%$ & 412 & 0.01 \\
Phitsanulok & $5.8 \%$ & 156 & $10.7 \%$ & 131 & 0.1 \\
\hline
\end{tabular}

${ }^{\text {a }} \mathrm{Hi}-\mathrm{IG}=$ poor higher income group

b Lo-IG $=$ poor lower income group. 
combination of what Kroeger (1983) called pathways models and determinants models, i.e. both local socio-cultural expressions of health systems and economic and other quantifiable determinants that may enhance or block access to services and therefore influence treatment-seeking strategies, and the presence or absence of UHC constitutes an essential framework in this regard. Our study shows that the inhabitants in the poor urban neighbourhoods in all three countries sought care from both public and private health facilities, but that the pattern varied in accordance with differences in 1 ) access to free or affordable public services, 2) the local composition of medical plurality, and 3) patterns of poverty. Spending per visit for the Lo-IG was lower than for the Hi-IG for most care sought. The two income groups faced almost the same incidence of payment difficulty even in Thailand where UHC is in place, but it was comparatively less in Thailand compared to the other sites. In Indonesia, the national health insurance law was introduced in 2004, and after seven years of delay, the Indonesian Court in 2011 ordered the Government to immediately implement the UHC law (Indonesian Institute for Social Security, 2012).

Private health facilities are important to the poor urban neighbourhoods, especially when the public sector is weak, but the quality of services should be monitored and heightened. In India, the near-total absence of public primary healthcare facilities has created a vacuum that has been filled by private providers, including providers without formal qualifications, and this situation gives cause for serious public health concerns (Seeberg, 2012). The linkages between universal coverage and medical pluralism are also noteworthy. The composition of a medically plural health system is impacted by the introduction of UHC in favour of registered and formally qualified biomedical (allopathic) providers. The absence of UHC in India has allowed for an uncontrolled market of diverse treatments without effective quality mechanisms in place. Medically trained providers may also provide sub-standard treatment (e.g. Uplekar et al., 1998) when supervision and training are primarily managed by the pharmaceutical industry (Kamat \& Nichter, 1998, Seeberg, 2012). In India, the twelfth five-year-plan in 2012 adopted UHC as one of the central themes for health. The plan commits public expenditure on health to be increased to $2.5 \%$ of gross domestic product from the current level of $1.1 \%$ and recommends adopting tax-based financing to generate additional resources required for supporting the expected increase in public health expenditure (Planning Commission of India, 2011). The Planning Commission also recommended that minimum $70 \%$ of public expenditure on health should be earmarked for primary healthcare. Our findings point for the need to link a future universal health coverage scheme to feasible mechanisms for monitoring and strengthening quality of services for private health sector providers at the primary healthcare level, including chemists and small health clinics manned by either medically qualified doctors or RMPs.

The disaggregate analysis has shown important variation within poor neighbourhoods, especially in terms of treatment-seeking strategies and catastrophic health expenditures. The study points to the need to find new ways to include marginalized population groups effectively and to protect them from local-level deprivation of resources that have been earmarked for them. UHC has successfully provided the urban poor in Thailand with access to public services, and a recent evaluation has recommended that the scheme is continued and strengthened (Health Systems Research Institute, 2012). However, our data shows a substantial difference between the two poor income groups even in Thailand. This study also points to a direct relationship between universal health coverage and the incidence of catastrophic healthcare expenditures, especially in combination with an over-reliance on the private health sector. Development of primary healthcare networks in poor neighbourhoods has been recommended to counteract catastrophic spending among the poor (Weraphong, Pannarunothai, Luxananun, Junsri, \& Deesawatsripetch, 2013).

Policy recommendations directly or indirectly emanating from this research include 1) development of effective quality control mechanisms, including accreditation for the private sector at primary healthcare level, in connections with introduction of UHC in India and Indonesia; 2) monitoring of the impact of UHC on the basis of disaggregate data (poor and poorest); 3 ) intervention research to test mechanisms to reach the poorest with UHC; and 4) inclusion of private providers without formal medical qualification in basic healthcare, based on continued education programmes.

\section{Acknowledgements}

The authors wish to acknowledge the crucial input and guidance for the project provided at various stages by Soenarto Sastrowijoto, Sri Suparyati Soenarto, Kusum Verma, Angkhanporn Sornngai and Aumnoay Pirunsarn. We also wish to record our gratitude to the research assistants who have been involved in data collection: Sasmita Sahani, Samir Diabagh, Rosalina Baral, Amita Kanungo, Braj Das, Amalia Muhaimin, Nur Azid Mahadinata, Onengan Caturanggani, Dwi Astuti, Antonius Sudiyanto, Aditya Nugoho, Deni Harbiyanto, Otojit Kshetrimayun, Yaoreiphy Horam, Kripabar Baruah, Subhas Nayak, Malvika Maheshwari, Birendra Suna, and Samaporn Suriyapong. Finally, we wish to thank the anonymous reviewers of earlier versions of this paper for their valuable contributions. We gratefully acknowledge the financial support provided by Danida for this research.

\section{Appendix A. Supplementary data}

Supplementary data related to this article can be found at http:// dx.doi.org/10.1016/j.socscimed.2013.11.039.

\section{References}

Barua, N., \& Pandav, C. S. (2011). The allure of the private practitioner: is this the only alternative for the urban poor in India? Indian Journal of Public Health, 55, 107.

Barua, N., Seeberg, J., \& Pandav, C. S. (2009). Health of the urban poor and role of private practitioners. The case of a slum in Delhi. New Delhi: AIIMS.

Census of India. (2011). Census of India. New Delhi: Registrar General and Census Commissioner.

Das, V., \& Das, R. K. (2006). Pharmaceuticals in urban ecologies. In A. Petryna, A. Lakoff, \& A. Kleinman (Eds.), Global pharmaceuticals: ethics, markets, practices (pp. 171-205). Durham \& London: Duke University Press.

Evans, C., \& Lambert, H. (1997). Health-seeking strategies and sexual health among female sex workers in urban India: implications for research and service provision. Social Science \& Medicine, 44, 1791-1803.

Health Systems Research Institute. (2012). Thailand's universal coverage scheme: Achievements and challenges. Nonthaburi: Health Systems Research Institute.

Indonesian Institute for Social Security. (2012). In Workshop seminar on DRG payment system and hospital cost structure. IJSI, Indonesian Hospital Association, Centre for Health Economics and Policy Analysis, Universitas Indonesia. Jogjakarta, Indonesia, 19-20 June 2012.

Janzen, J. M. (1987). Therapy management: concept, reality, process. Medical Anthropology Quarterly, 1, 68-84.

Kamat, V. R., \& Nichter, M. (1998). Pharmacies, self-medication and pharmaceutical marketing in Bombay, India. Social Science E Medicine, 47, 779-794.

Koulovatianos, C., Schröder, C., \& Schmidt, U. (2005). Properties of equivalence scales in different countries. Journal of Economics, 86, 19-27.

Kroeger, A. (1983). Anthropological and socio-medical health care research in developing countries. Social Science \& Medicine, 17, 147-161.

Krongkaew, M. (2003). In A brief note on poverty in Thailand. Paper presented the seminar organized by the Economic Society of Thailand at Naresuan University, Phitsanulok, 31 July 2003.

Limwattananon, S., Tangcharoensathien, V., \& Prakongsai, P. (2007). Catastrophic and poverty impacts of health payments: results from national household surveys in Thailand. Bulletin of the World Health Organization, 85, 600-606.

Limwattananon, S., Tangcharoensathien, V., Tisayaticom, K., Boonyapaisarncharoen, T., \& Prakongsai, P. (2012). Why has the universal coverage scheme in Thailand achieved a pro-poor public subsidy for health care? BMC Public Health, 12, S6. 
Merlis, M., \& Fund, C. (2002). Family out-of-pocket spending for health services: A continuing source of financial insecurity. Commonwealth Fund.

Pannarunothai, S., \& Mills, A. (1997). Characteristics of public and private healthcare providers in a Thai urban setting. In S. Bennett, B. McPake, \& A. Mills (Eds.) Private health providers in developing countries. Serving the public interest? London: Zed Books.

Pannarunothai, S., \& Mills, A. (1998). Researching the public and private mix in healthcare in a Thai urban area: methodological approaches. Health Policy and Planning, 13, 234-248.

Planning Commission of India. (2011). High level expert group report on universal health coverage for India. New Delhi.

Seeberg, J. (2012). Connecting pills and people: an ethnography of the pharmaceutical nexus in Odisha, India. Medical Anthropology Ouarterly, 26, 182-200.

Seeberg, J. (2013). The death of Shankar: tuberculosis and social exclusion in a poor neighbourhood in Bhubaneswar, Odisha. In K. B. Nielsen, M. F. Qvortrup, \& U. Skoda (Eds.), Navigating social exclusion and inclusion in contemporary India and beyond (pp. 207-226). London: Anthem.

Statistical Body of Jogjakarta/BPS. (2010). Census statistics of 2010. Badan Pusat Statistik.
Su, T., Kouyaté, B., \& Flessa, S. (2006). Catastrophic household expenditure for healthcare in a low-income society: a study from Nouna district, Burkina Faso. Bulletin of the World Health Organization, 84, 21-27.

Uplekar, M., Juvekar, S., Morankar, S., Rangan, S., \& Nunn, P. (1998). Tuberculosis patients and practitioners in private clinics in India. International Journal of Tuberculosis and Lung Disease, 2(4), 324-329.

Van Doorslaer, E., O’Donnell, O., Rannan-Eliya, R. P., Somanathan, A., Adhikari, S. R., Garg, C. C., et al. (2007). Catastrophic payments for healthcare in Asia. Health Economics, 16, 1159-1184.

Vlahov, D., Freudenberg, N., Proietti, F., Ompad, D., Quinn, A., Nandi, V., et al. (2007). Urban as a determinant of health. Journal of Urban Health, 84, 16-26.

Weraphong, J., Pannarunothai, S., Luxananun, T., Junsri, N., \& Deesawatsripetch, S. (2013). Catastrophic health expenditure in an urban city: seven years after universal coverage policy in Thailand. Southeast Asian Journal of Tropical Medicine and Public Health, 44, 124-136.

World Bank. (2003). Country assistance strategy progress report. Washington, D.C. The World Bank.

World Bank. (2013). Atlas of global development. World Bank. 